\title{
TENSILE STRENGTH OF BONDING MATERIAL TO DENTINE USING WATER-WET AND ETHANOL-WET TECHNIQUES
}

\author{
Ainin Nafilatus, ${ }^{1}$ M. Mudjiono ${ }^{2}$, Widya Saraswati ${ }^{2}$ \\ 1. Course of Dentistry, Airlangga University, Surabaya-Indonesia \\ 2. Department of Conservation Dentistry, Airlangga University, Surabaya-Indonesia
}

\begin{abstract}
Background: Composite resins have hydrophobic properties so it cannot attach to dentine. Moist dentin is a normal condition caused by the presence of fluid in dentinal tubules. Therefore bonding material is required to bond dentine with composite. Water-wet technique is a technique in which dentine surface is rinsed after etching by using water and allowing it to be moist and prevent the collapse of dentine collagen fibrils. This technique is commonly used today, but excess water disturbs the effectiveness of dentine and bonding material attachment. Ethanol-wet technique is a technique in which ethanol is used to replace water before bonding to reduce excess water in dentine surface. This technique will initiate monomer penetration into interfibrillar space of dentine. It will affect the result of tensile strength test. Purpose: The purpose of this study was to compare tensile strength of bonding material to dentine using water-wet and ethanol-wet techniques. Method: 12 samples of bovine incisors teeth were randomly divided into 2 group. Each group consists of six samples. Group 1 was treated with water-wet technique and group 2 was treated with ethanol-wet technique. Autograph was used as a tensile strength test instrument. Result : The average of tensile strength using water-wet technique was 2,16067 MPa and ethanol-wet technique was 4,21900 MPa. Conclusion: Ethanol-wet technique have higher value of tensile strength than water-wet technique.
\end{abstract}

Keywords: bonding material, water-wet technique, ethanol-wet technique

Correspondence : Widya Saraswati, Fakultas Kedokteran Gigi, Universitas Airlangga, widya_s@ fkg.unair.ac.id, $+6287851592969$

\section{INTRODUCTION}

Dentin bonding agents are resin materials used to make a dental composite filling material adhere to bond to both dentine and enamel ${ }^{1}$. Composite resins have hydrophobic properties so it cannot attach to dentine. Moist dentin is a normal condition caused by the presence of fluid in dentinal tubules. Therefore bonding material is required to bond dentine with composite. Bonding material can bind to dentine by mechanical bonding, chemical bonding or both. Micromechanical bond to dentine obtained by penetration of adhesive material into dentinal collagen fibers. ${ }^{3}$
Water-wet technique is a technique in which dentine surface is rinsed after etching by using water and allowing it to be moist and prevent the collapse of dentinal collagen fibrils. ${ }^{4}$ This technique is commonly used today, but excess water disturbs the effectiveness of dentine and bonding material attachment. The presence of organic solvent such as ethanol can replace water from dentinal surface so it can initiate penetration of monomer into the dentinal collagen fibrils. ${ }^{3}$

If there is excess water, the remaining water prrevent contact between resin and collagen fibrils. Because too much water around the collagen fibrils will 
form hydrogen bond between water and collagen amino which inhibit bonding between adhesive material and dentinal collagen. Poor collagen fibrils bond was susceptible to hydrolized by matrix metalloproteinases (MMPs). ${ }^{4,5}$ MMPs was group of zinc proteolytic enzymes which can degrade organic matrix from dentine after demineralization. ${ }^{6}$

Previous research has shown that ethanol-wet technique can increase resin infiltration that cause increasing of hybrid layer quality when compared to water-wet technique, so the bond strength increased. ${ }^{7}$ Ethanol-wet technique is a technique in which ethanol is used to replace water before bonding to reduce excess water in dentine surface. ${ }^{8}$ Several recent studies have evaluated the possibility of water replacement with ethanol on etching dentin. According to Heymann (2013) after acid etching was applied to dentine and then rinsed with $100 \%$ ethanol, the strength of hydrophilic or hydrophobic resin increased significantly. ${ }^{3}$ The main principles of ethanolwet is to infltrate the interfbrillar spaces and dentinal tubules with hydrophobic dimethacrylate resins. ${ }^{9}$

Hosaka et al. (2009) showed that using $100 \%$ ethanol for 60 seconds in ethanol-wet technique can increase resin infiltration and increase resin attachment with collagen fibrils seen through TEM, thus minimize MMPs activity. Thus increase the strength and durability of dentin-bonding bonds after a study in aqueous environment for 12 months. Sadek et al. (2010) evaluated that hydrophobic resins were better than hydrophilic resins to increase the resin-dentine bond resistance after study for 12 months. Yesilyurt et al. (2015) found that ethanol-wet technique can increase the resin-dentin bond resistance using a total-etch bonding material. Likewise, Li et al., (2012) found that ethanol-wet technique can increase the bond resistance of dentin resins. This can be achieved in $100 \%$ ethanol application for 60 seconds, but the effect of the pulp was negligible in the study. ${ }^{10}$

According to explanation above, the surfaces of etched dentine can be cleaned by wet-bonding techniques and several studies have shown that water and ethanol use may affect the strength between adhesive resin and dentine collagen fibrils. Therefore, the author was interest to researching about the different usage of water-wet and ethanol-wet technique on tensile strength of bonding material to dentine.

\section{MATERIALS AND METHOD}

The type of this research is laboratory experimental research with post test only group design research. The samples used in this study were bovine teeth (incisors) that no cracked, caries-free and non-abrasion parts obtained from slaughterhouses at Jalan Pegirian, Surabaya. The sample number used in this study is at least 6 in each group with selective random sampling. Independent variable in this research were the type of bonding technique, namely water-wet technique and ethanol-wet tecnique. Dependent variable in this study was tensile strength. Controlled variable in this study were the types of dentin bonding materials, techniques used in the study, the types of teeth, the shape and size of the samples, the way in which the samples were prepared, and the means and tools used to measure the tensile strength. The research was conducted at the laboratory of Airlangga University Surabaya.

The materials used in this study were bovine teeth (incisivus), 3M Single Bond 2 Adhesive etch bonding material, $37 \%$ phosphoric acid 3M Scotchbond Etchant, aquadest, pure ethanol, saline 
solution, dental stone, and vaseline. The tools used in this research include the tensile strength instrument Autograph AG10TE (Shimadzu, Japan) in LDB-Unair, plunger set, low-speed contra-angle handpiece, micromotor, bur fissure, diamond bur disc, tweezers, light curing unit, beaker glass, microbrush, chip blower, plastic filling instrument, cotton pellet, insulation, abrasive paper, glass lab, and cylinder mold.

The first, tooth cleansed using a brush. During cleaning, the teeth are always wet. Then the tooth is soaked in saline or PZ solution to give an atmosphere like in the oral cavity until it is ready for preparation. Tooth crown is cut to the cervical with diamond disk bur. The buccal area of crown is prepared until the dentine form a flat plane using fissure bur and contra angle hand piece in the same direction according to the plunger mold. The size of cylinder molds were $10 \mathrm{~mm}$ in diameter and $5 \mathrm{~mm}$ in height, smeared with vaseline and placed on top of glass lab as the base, bovine teeth are positioned in the center at the base of the mold.

Powder and liquid of gips are mixed with $\mathrm{w}: \mathrm{p}$ ratio according to the manufacturer's instructions, inserted into the mold up less than $5 \mathrm{~mm}$ of height. Then dentine inserted into the gips. Dentin surface facing up and cleaned from the remaining gips and rubbed with a waterproof abrasive paper with a P600 roughness under flowing water. The treated dentine restricted by adhesive tape perforated in the center of dentine surface. The sample randomly divided into 2 groups. Group A used water-wet technique that applied the dentine with $37 \%$ acid etching material using microbrush for 15 seconds. After that dentin rinsed aquadest for \pm 10 seconds then kept moist condition with cotton pellet. 2 drops ( 0.02 grams) of dentin bonding material dripped on microbrush, then aplicate to dentine and left for 20 seconds. Next sprayed with air spray from the blower chip for 5 seconds to remove the excess water, then curing for 10 seconds.

Group B using ethanol-wet technique is dentine applied with $37 \%$ acid etching material using microbrush for 15 seconds, then rinsed with aquadest for \pm 10 seconds and kept moist condition with cotton pellet, applied $2 \mathrm{ml}$ of pure ethanol for 1 minute (Hosaka et al., 2009) using syringe with and treated with cotton pellets. Next 2 drops (0.02 grams) of dentin bonding materials is dripped onto the disposable brush, applied to dentine and left for 20 seconds. Spray using blower chip for 5 seconds to remove the excess solvent, then curing for 10 seconds. Then the cylinder mold of each group is inserted into the lower plunger and fixed by locking. The mold on upper plunger fill with composite then put with the lower plunger and fixed by locking. Then cure for 20 seconds on both sides of the plunger, each 10 seconds. Then tensile strength tested with the AG-10 TE Shimadzu, Japan. The plunger set is placed on the autograph with the lower plunger fixed on the bottom of grip and the upper plunger is fixed on the top of grip. Then removed lock on the upper plunger. With cross head speed $10 \mathrm{~mm} / \mathrm{min}$. The instrument runs until the upper plunger and lower plunger was separated and the numbers on the load cell stable. The results seen on the autograph screens AG-10 TE Shimadzu has a unit of kgf. $1 \mathrm{kgf}=9,81 \mathrm{~N}$, $1 \mathrm{Mpa}=1 \mathrm{~N} / \mathrm{mm} 2$, range: 5, load cell capacity: $5 \mathrm{kN} / 500 \mathrm{kgf}$, dentin surface area try $=\pi \mathrm{r} 2=12.56 \mathrm{~mm} 2$. The numbers read at the time of sampling was calculated by the formula ${ }^{11}$ : 


$$
\text { Tensile strength }\left(\frac{N}{\mathrm{~mm}^{2}}\right)=\frac{\text { Tools value }}{\text { Sample cross section area }}
$$

Data analysis using Kolmogorov Smirnov test to see the distribution of data. Levene test to see the homogeneity of the data.

If the distribution of data was normal and homogeneous then using Independent TTest because the data type is the parametric ratio of the 2 free groups. The two free groups are two unpaired groups, meaning the source data comes from a different subject with a significance level $(\alpha)=0.05$.

\section{RESULTS}

The measurements shown on the monitor of the autograph was the tensile strength of the bonding material required to separate from the tooth surface in Newton (N) units, then calculated in units of Mega Pascal (MPa) using tensile strength formula $\mathrm{N} / \mathrm{mm} 2=\mathrm{F} / \mathrm{A}$. With $\mathrm{N} / \mathrm{mm} 2=$ tensile strength $(\mathrm{MPa}), \mathrm{F}=$ tensile force $(\mathrm{N})$, and $\mathrm{A}$ $=$ sample surface area $\left(\mathrm{mm}^{2}\right)$. For the surface area in all samples was $12.56 \mathrm{~mm}^{2}$. Based on data collecting of tensile strength bonding material to dentin using water-wet and ethanol-wet technique, we get the result of tensile strength average value in table 5.1. So we get the difference of tensile strength of the bonding material to dentin using water-wet and ethanol-wet technique was $2.05833 \mathrm{MPa}$.

Table 5.1 Mean of tensile strength bonding material to dentine using water-wet and ethanolwet techniques (MPa).

\begin{tabular}{|c|c|c|c|}
\hline Kelompok & $\mathrm{N}$ & $\overline{\mathrm{x}}$ & SD \\
\hline I & 6 & 2,16067 & 0,522833 \\
\hline II & 6 & 4,21900 & 0,285179 \\
\hline
\end{tabular}

Information :

$\begin{array}{ll}\mathrm{N} & : \text { Number of samples } \\ \overline{\mathrm{X}} & : \text { Average value } \\ \mathrm{SD} & : \text { Standard deviation }\end{array}$

Group I : Tensile strength of bonding material to dentine using the water-wet technique Group II : Tensile strength of bonding material to dentine using ethanol-wet technique

\section{DISCUSSION}

This research was done to know the difference about tensile strength of bonding material to dentine using water-wet and ethanol-wet technique. The value of tensile strength was seen based on the tensile force given between bonding material and dentine. Tensile strength was attachment strength between the bonding material applied to the dentine surface using waterwet and ethanol-wet technique then attached with composite. Water-wet technique was done by rinsing the dentin surface after etching using water and absorbing it with cotton pellets to keep moist dentine. While on ethanol-wet technique used ethanol to rinse the etching dentine to replace water before bonding.

Based on the results of statistical data analysis using Independent $\mathrm{T}$-Test showed that there was a significant difference in tensile strength of bonding material to dentin using water-wet and ethanol-wet techniques. From the mean value of tensile strength it can be seen that tensile strength of bonding material to dentine using ethanol-wet technique is greater than using water-wet technique. Because organic solvents such as ethanol was known to replace water on the dentine 
surface to reduce excess water in the dentine and initiate monomer penetration into dentin collagen interfibrillar space resulting a hybrid layer. This technique called ethanol-wet technique. Bonding material can bind to dentine by mechanical bonding, chemical bonding or both. Micromechanical bond to dentine obtained by penetration of adhesive material into dentinal collagen fibers. ${ }^{3}$

Total etch bonding system combines primers and adhesives into a solution with a separate acid etching process which dissolves the entire smear layer and hydrixy-apatite and washed to remove smear layer and salts after etching. Total-etch system used 30-40\% phosphoric acid to dissolve smear layer, hydroxyapatite and denatured collagen about $2 \mu \mathrm{m}$, dentin intertubular decalsification with depth of 1-5 micrometers. Opening the tubules of dentin and collagen will make more infiltration of bonding resin into dentin collagen resulting in increasing of mechanical and chemical bonding bonds with amino dentin. ${ }^{12}$

Principles of ethanol-wet are explained by using Hoy's triple solubility parameter theory in. Hoy's triple solubility parameters consist of dispersive forces $(\delta \mathrm{d})$, polar forces $(\delta \mathrm{p})$, hydrogen bonding forces $(\delta \mathrm{h})$, and total cohesive forces $(\delta \mathrm{t})$. Solubility parameters for hydrogen bonding forces $(\delta \mathrm{h})$ are used to predict how any solvent or adhesive resin can re-expand a collapsed dried, acid-etched dentin. When demineralized dentin matrices collapsed (dried dentin), to re-expand matrices again, a solvent or resin monomer blends with a higher hydrogen bonding force than 14.8 $(\mathrm{Jcm} 3) 1 / 2$ is needed. Ethanol $(\delta \mathrm{h}=20.0$ $[\mathrm{Jcm} 3] 1 / 2)$ and water $(\delta \mathrm{h}=40.4[\mathrm{Jcm} 3] 1 / 2)$ are successful in breaking interpeptide hydrogen bonds allowing the matrix to soften to the point that it can expand. Most monomers used in adhesive dentistry have $\delta$ h values below those of dried dentin. Thus, in their neat form, such resins cannot expand dried, acid-etched dentin. Water-wet-bonding expands the dried dentin maximally because water has a very high $\delta$ h value of $40(\mathrm{Jcm} 3) 1 / 2$. When water in the wet interfibriller diffuse with ethanol, more hydrophobic liquid is generated within the collagen matrix. ${ }^{9}$

According to Ayar, (2016) when ethanol replaces water higher infiltration generated because the hydrogen interpeptide bonds are stronger than waterwet techniques due to enough re-expansion so that the bonding resin get into collagen fibrils. In the water-wet technique, when water evaporates, the weak interpeptide hydrogen bonds due to over-reinforcement ( $\delta$ h 40.0) occur. The presence of water causes a low resin-dentin stiffness value and the surface tension of collagen matrix decreases causes weak resin-dentin bond strength. 9,10

Solubility parameter theory has also been used to predict the miscibility of two different solutions by comparing their total cohesive forces $(\delta \mathrm{t})$. It predicts that if there is $<5(\mathrm{Jcm} 3) 1 / 2$ between the solubility parameter for the total cohesive energy $(\delta \mathrm{t})$ of a solution and a second solution or a substrate that the solution will wet the substrate and cause it to swell enough to permit entry of the solution. It was shown that discrepancies in $\delta \mathrm{t}$ values of hydrophobic resin monomers with water-wet matrices are $>5(\mathrm{Jcm} 3) 1 / 2$ while solubility parameters of hydrophobic resin match better with those of ethanol-saturated dentin matrices. This shows that ethanol can mix with resin-dentin causes greater resin-dentin bond strength because ethanol get into the substrate. This research occurs if the resin is applied with $100 \%$ ethanol. ${ }^{9}$ 
After etching will form intrafibrilar and interfibrilar space then water fill the space, after applied adhesive and resin monomer will replace water in the space. However, not all incoming resin monomers replace water in the vicinity of collagen fibrils, this is one of cause that makes the strength of composite resins reduced. If there is excess water, the remaining water prevents contact between resin and collagen fibrils. $^{4}$

Hosaka et al,, (2009) research showed that using $100 \%$ ethanol for 60 seconds in ethanol-wet technique can increase resin infiltration and increase resin attachment with collagen fibrils seen through TEM, thus minimizing MMPs activity. Yesilyurt et al., (2015) found that ethanol-wet technique can increase the resin-dentin bond resistance using totaletch bonding agent because ethanol can help the penetration of hydrophobic resins in dentine. Li et al., (2012) found that ethanol-wet technique can increase the bond resistance of dentin resins. This can be achieved in a $100 \%$ ethanol application for 60 seconds, but the effect on the pulp is not examined in the study. ${ }^{10}$

In this research, the standard deviation value of water-wet is 0.285179 and ethanol-wet is 0.522833 . The standard

\section{BIBLIOGRAPHY}

1. Gupta S, Kaur G, Biswal SS, Kaushik SV, Karami S, Goyal S, Singh S. 2014. Dentin Bonding Agents: An Overview. $J$ Adv Med Dent Science. 2(1): pp. 82-84.

2. Anusavice, KJ. 2003. Philip's Science of Dental Material $11^{\text {th }} E d$. USA:WB Elsevier, Saunders Company. pp. 21,24,79,251- 9,227 - 32 .

3. Heymann, Herald O et al. 2013. Art and Sciences of Operative Dentistry Sixth Edition. Canada : Elsevier deviation value of tensile strength varies indicating that not only complex tests but also sensitivity in the workmanship and manipulation of adhesive materials and composite resins, due to manual processing procedures it must be more carefully and controlled. It is also influenced by dental specimens used, dental age, medium and storage time, depth of dentine, mineral content in the tooth, morphological variation, micro hardness, smear layer thickness, and dentin elastic modulus affecting adhesive strength of dentin. ${ }^{13}$

One of causes low tensile strength values is the study did not used the dentine moisture in detail. optimum humidity was generated by absorbing water with cotton pellets to prevent over-wet phenomenon. No specific moisture measurements of dentine, so the possibility of dentin is not completely dry yet in the drying process, over-wet phenomenon still occurs. The presence of high concentrations of ethanol for 60 seconds may cause dentine too dry due to excessive water replacement by ethanol. Both of these possibilities can decrease the interaction of bonding resin with dentin collagen fibrils caused decreasing of attachment strength. In the study also neglected the reaction of the pulp, it can possible sensitivity on the pulp due to ethanol.

4. Nagpal R, Manuja N,Pandit IK. 2015. Effect of ethanol wet bonding technique on the durability of resin dentin bond with contemporary adhesive systems. The Journal of Clinical Pediatric Dentistry. 39 (2): pp. 133-142.

5. Adioro, S. 2013. Penggunaan Resin Komposit dalam Bidang Konservasi Gigi. Surabaya: PT. Revka Petra Media. pp. 17-18, 45, 57, 104-6.

6. Attathom, T. 2009. Effect of Ethanol Wet-Bonding to Caries Affected Dentin. thesis, University of Iowa. pp. 19-28. 
7. Shin TP, Yao X, Huenergardt R, Walker MP, Wang Y. 2009. Morphological and chemical characterization of bonding hydrophobic adhesive to dentin using ethanol wet bonding technique. Dent Mater;25: pp. 1050-7.

8. Subramani K \& Ahmed W \& Hartsfield J K. 2013. Nanobiomaterilas in Clini,;;cal Dentistry. USA : Elsevier: p. 153.

9. Pashley, D. H.; Tay, F. R.; Carvalho, R. M.; Rueggeberg, F. A.; Agee, K. A.; Carrilho, M.; Donnelly, A. \& Garc.aGodoy, F. 2007. From dry bonding to water-wet bonding to ethanol-wet bonding. A review of the interactions between dentin matrix and solvated resins using a macromodel of the hybrid layer. Am. J. Dent., 20(1): pp. 7-20.
10.Ayar, Muhammet Kerim. 2016. A review of ethanol wet-bonding: Principles and techniques. Eur J Dent (10): pp. 155-9.

11.Mangonon. P.L. 1999. The Principles of materials Selection for Engineering Design. Printice-Hall International,Inc. Hal- 29 -81. McCabe JF, Walls AWG. Applied Dental Materials 9thed, UK:Blackwell. pp. 225-9.

12.Christensen. 2006. Has the total etch concept disspeared. American Dental Association J. 137(6): p. 817

13.Tulunoglu O, Tulunoglu I. 2008. Resindentin interfacial morphology and shear bond strengths to primary dentin after long-term water storage: An in vitro study. Quintessence International; 39(5): pp. 427-37. 